\title{
TGF- $\beta /$ Smad3 inhibit vascular smooth muscle cell apoptosis through an autocrine signaling mechanism involving VEGF-A
}

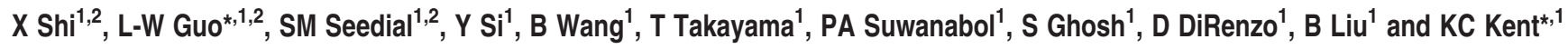

We have previously shown that in the presence of elevated Smad3, transforming growth factor- $\beta$ (TGF- $\beta$ ) transforms from an inhibitor to a stimulant of vascular smooth muscle cell (SMC) proliferation and intimal hyperplasia (IH). Here we identify a novel mechanism through which TGF- $\beta /$ Smad3 also exacerbates IH by inhibiting SMC apoptosis. We found that TGF- $\beta$ treatment led to inhibition of apoptosis in rat SMCs following viral expression of Smad3. Conditioned media from these cells when applied to naive SMCs recapitulated this effect, suggesting an autocrine pathway through a secreted factor. Gene array of TGF- $\beta /$ Smad3treated cells revealed enhanced expression of vascular endothelial growth factor (VEGF), a known inhibitor of endothelial cell apoptosis. We then evaluated whether VEGF is the secreted mediator responsible for TGF- $\beta / S m a d 3$ inhibition of SMC apoptosis. In TGF- $\beta$ /Smad3-treated cells, VEGF mRNA and protein as well as VEGF secretion were increased. Moreover, recombinant VEGFA inhibited SMC apoptosis and a VEGF-A-neutralizing antibody reversed the inhibitory effect of conditioned media on SMC apoptosis. Stimulation of SMCs with TGF- $\beta$ led to the formation of a complex of Smad3 and hypoxia-inducible factor-1 $\alpha$ (HIF-1 $1 \alpha)$ that in turn activated the VEGF-A promoter and transcription. In rat carotid arteries following arterial injury, Smad3 and VEGF-A expression were upregulated. Moreover, Smad3 gene transfer further enhanced VEGF expression as well as inhibited SMC apoptosis. Finally, blocking either the VEGF receptor or Smad3 signaling in injured carotid arteries abrogated the inhibitory effect of Smad3 on vascular SMC apoptosis. Taken together, our study reveals that following angioplasty, elevation of both TGF$\beta$ and Smad3 leads to SMC secretion of VEGF-A that functions as an autocrine inhibitor of SMC apoptosis. This novel pathway provides further insights into the role of TGF- $\beta$ in the development of IH.

Cell Death and Disease (2014) 5, e1317; doi:10.1038/cddis.2014.282; published online 10 July 2014

Restenosis is the leading cause of failure of vascular reconstructions. Intimal hyperplasia $(\mathrm{IH})$, the primary contributor to restenosis, is a complex process through which enhanced vascular smooth muscle cell (SMC) proliferation, migration and inhibition of apoptosis lead to the development of a highly cellular plaque impinging on the vessel lumen. ${ }^{1-3}$

Vascular SMC apoptosis plays a critical role in the development of $\mathrm{IH}$; it inhibits $\mathrm{IH}$ by reducing cell number. ${ }^{4-7}$ SMC apoptosis develops immediately following angioplasty and continues for up to 4 weeks. ${ }^{8,9}$ Proliferation and apoptosis of vascular SMCs after vascular intervention are opposing forces that are intimately coupled to regulate absolute cell number, ultimately determining whether a restenotic lesion develops. ${ }^{8,10}$ Apoptosis is stimulated by factors such as oxidative stress, mitochondria leakage or by damaged DNA. UV irradiation is one of the commonly used methods to experimentally induce apoptosis through oxidative stress and through its effect on DNA. ${ }^{11}$
Transforming growth factor- $\beta$ (TGF- $\beta$ ) is a pleiotropic cytokine that binds to type I and II receptors and signals through both Smad-dependent and Smad-independent pathways. $^{12}$ The effect of TGF- $\beta$ and Smad3 is dependent upon cell type, cell density as well as conditions of culture..$^{5,13,14}$ Classically, TGF- $\beta$ is thought to be a growth inhibitor that induces cell cycle arrest as well as apoptosis ${ }^{15}$ and suppresses proliferation and migration of cultured vascular SMCs. ${ }^{16-18}$ However, TGF- $\beta$ after angioplasty increases SMC proliferation in the arterial wall. ${ }^{19,20}$ We have recently discovered that in the context of elevated Smad3, TGF- $\beta$ is transformed from an inhibitor to a stimulant of SMC proliferation, leading to enhancement of $\mathrm{IH}^{2,21}$

Vascular endothelial growth factor (VEGF) is a family of heparin binding glycoproteins with potent angiogenic function. The VEGF family consists of five structurally related ligands that bind differentially to their receptors (VEGFR-1, -2 and -3$).{ }^{22}$ Among these five VEGF family members, the best

\footnotetext{
${ }^{1}$ Department of Surgery, University of Wisconsin, 1111 Highland Avenue, WIMR Building, Madison, WI 53705, USA

${ }^{*}$ Corresponding authors: L-W Guo, Department of Surgery, University of Wisconsin, 1111 Highland Avenue, WIMR Building, Madison, WI 53705, USA. Tel: + 1608262 6269; Fax: + 1608262 3330; E-mail: guo@ surgery.wisc.edu

or KC Kent, Department of Surgery, University of Wisconsin Hospital and Clinics, 600 Highland Avenue, Madison, WI 53792-7375, USA. Tel: +1 608 265 8854; Fax: +1 608265 5963; E-mail: kent@surgery.wisc.edu

${ }^{2}$ These authors contributed equally to this work.

Abbreviations: TGF- $\beta$, transforming growth factor- $\beta$; AdGFP, adenovirus for expression of green fluorescent protein; AdSmad3, adenovirus for expression of Smad3; VEGF, vascular endothelial growth factor; IP, immunoprecipitation; IH, intimal hyperplasia; SMC, smooth muscle cell; HIF- $1 \alpha$, hypoxia-inducible factor-1 $\alpha$; FLT-1, fmsrelated tyrosine kinase; VEGFR, vascular endothelial growth factor receptor; PDGF, platelet-derived growth factor; ChIP, chromatin immunoprecipitation; TUNEL, terminal deoxynucleotidyl transferase-mediated dUTP nick end labeling assay; ANOVA, analysis of variance; siRNA, small interfering RNA

Received 27.1.14; revised 26.5.14; accepted 28.5.14; Edited by A Stephanou
} 
studied is VEGF-A that has potent angiogenic effects in several pathophysiological processes, such as wound healing and tumor metastasis. Traditionally, VEGF-A is considered an endothelial-specific growth factor important in vascular development and in the maintenance of endothelial integrity. However, there is also evidence suggesting that VEGF receptors (fms-related tyrosine kinase (FLT-1)) are also expressed and may have discrete functions in other cell types including SMCs. ${ }^{23-25}$

The effect of TGF- $\beta$ on vascular SMC apoptosis has been explored and classically TGF- $\beta$ has been found to be an inhibitor of apoptosis. However, the effect of TGF- $\beta$ on apoptosis in the context of arterial injury has not been evaluated. The focus of this study was to determine the role of TGF- $\beta$ and Smad3 in SMC apoptosis in vitro and in arteries following angioplasty. Our data reveal a novel pathway through which elevated TGF- $\beta /$ Smad3 contributes to $\mathrm{IH}$ by inhibiting vascular SMC apoptosis through a mechanism involving SMC secretion of VEGF-A.

\section{Results}

TGF- $\beta$ /Smad3 inhibits vascular SMC apoptosis through a secreted factor. Our group and others have shown that both TGF- $\beta$ and its signaling protein Smad3 are elevated in injured arteries in both humans and animals. ${ }^{2,26}$ As SMC apoptosis plays a crucial role in $\mathrm{IH}$, we investigated whether TGF- $\beta /$ Smad3 also regulates $\mathrm{IH}$ through an effect on SMC apoptosis. Cultured vascular SMCs were infected with adenoviral vectors expressing Smad3 (AdSmad3; or green fluorescent protein (AdGFP)) followed by stimulation with TGF- $\beta$. SMC apoptosis was induced with UV light and apoptosis was analyzed by flow cytometry. We found that the SMC apoptotic index (Annexin-V + /7AAD - ) decreased significantly (by $\sim 50 \%$ ) following Smad3 upregulation and treatment with TGF- $\beta$ (Figure 1a), whereas TGF- $\beta /$ Smad3 treatment alone (without UV light) had no effect on SMC apoptosis (Supplementary Figure S1). Inhibition of SMC apoptosis by AdSmad3/TGF- $\beta$ was confirmed by additional studies using either $\mathrm{H}_{2} \mathrm{O}_{2}$ to induce apoptosis and enzymelinked immunosorbent assay (ELISA) for DNA fragmentation for quantification, or TNF- $\alpha /$ cycloheximide to induce apoptosis and immunoblotting of cleaved caspase 3 to quantify (Supplementary Figure S2).

To differentiate whether this is a direct effect of Smad3 on SMCs or an indirect effect through an autocrine mechanism involving a secreted factor, conditioned media from vascular SMCs treated with TGF- $\beta /$ Smad3 or controls were applied to naive vascular SMCs. Then, UV-induced apoptosis was assessed by flow cytometric analysis. The data reveal that conditioned media from Smad3-expressing, TGF- $\beta$-stimulated vascular SMCs significantly inhibited vascular SMC apoptosis (Figure 1b). The antiapoptotic effect of the conditioned media was similar to that observed following direct application of TGF- $\beta /$ Smad3 to vascular SMCs. Taken together, these results demonstrate that a secreted factor (or a

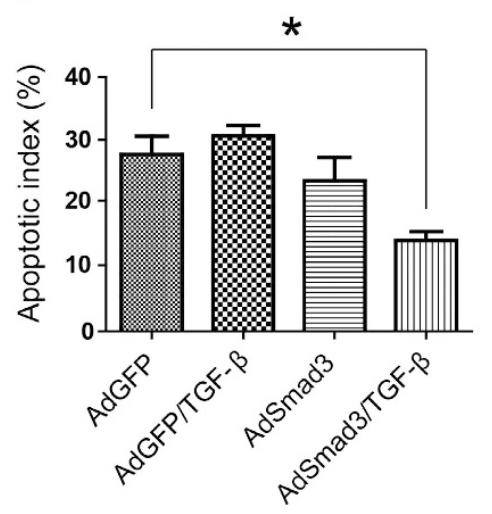

C

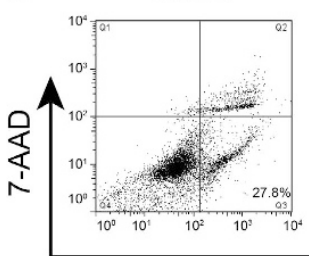

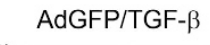

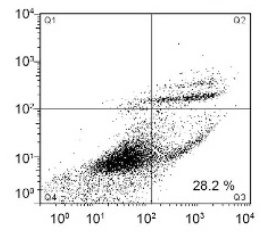

b
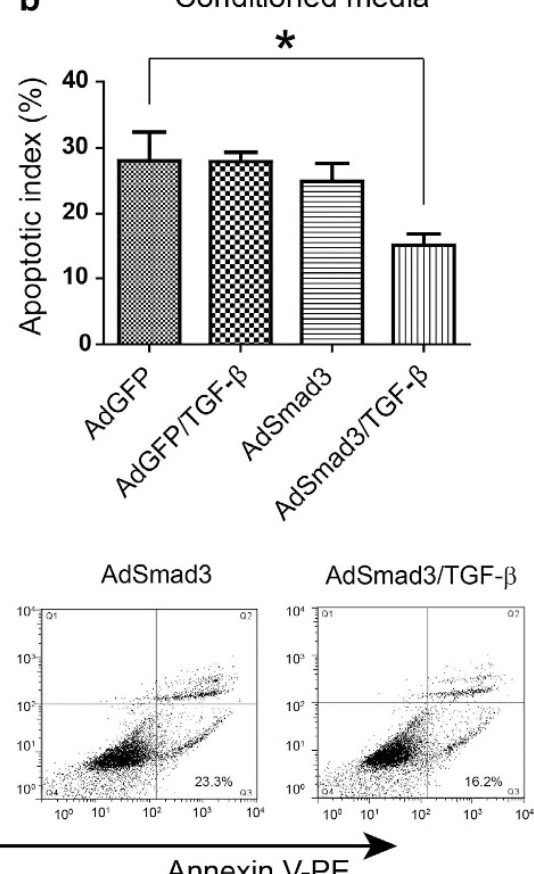

Figure 1 TGF- $\beta /$ Smad3 treatment inhibits UV-induced apoptosis in vascular smooth muscle cells (SMCs) through a secreted factor. (a) Rat vascular SMCs were infected with either control virus (AdGFP) or AdSmad3 followed by stimulation with TGF- $\beta(5 \mathrm{ng} / \mathrm{ml})$ for $48 \mathrm{~h}$. SMC apoptosis was then induced by exposure to UV light for $5 \mathrm{~min}$ and apoptotic index was measured $6 \mathrm{~h}$ later by flow cytometric analysis for Annexin V and 7-AAD staining, as described in the Materials and Methods. Each bar represents mean \pm S.E.M. of three independent experiments ( ${ }^{*} P<0.05$ compared with AdGFP control). (b) Rat vascular SMCs were infected with either AdGFP or AdSmad3 followed by stimulation with TGF- $\beta(5 \mathrm{ng} / \mathrm{ml})$ for $48 \mathrm{~h}$, and conditioned media were collected and applied to naive vascular SMCs for $12 \mathrm{~h}$. Apoptosis was then induced by exposure to UV light for $5 \mathrm{~min}$ and apoptotic index was measured after a 6 -h continued incubation in the conditioned media. Each bar represents mean \pm S.E.M. of three independent experiments ( ${ }^{*} P<0.05$ compared with the treatment with the conditioned media from AdGFP-expressing SMCs). (c) Representative FACS plots for (a) 
factors) is responsible for TGF- $\beta /$ Smad3-induced inhibition of SMC apoptosis.

TGF- $\beta /$ Smad3 stimulate VEGF-A expression in VSMCs. To determine the identity of the factor that mediates inhibition of SMC apoptosis, we performed a microarray analysis on cultured SMCs treated with TGF- $\beta /$ Smad3 or AdGFP. We found that the expression of VEGF-A, a growth factor with antiapoptotic function, was increased by 7.7 -fold after TGF- $\beta$ / Smad3 stimulation. This increase was substantially higher than that of other growth factors such as platelet-derived growth factor (PDGF-BB) and fibroblast growth factor (FGF-2) that are also potentially antiapoptotic (Supplementary Table S1). The findings with these additional growth factors have since been confirmed by RT-PCR (data not shown). We then explored the VEGF-A isoforms that are expressed in SMCs and found that VEGF-164 mRNA levels increased significantly in Smad3-overexpressing SMCs in a timedependent manner following treatment with TGF- $\beta$ (Figure 2a). Moreover, after TGF- $\beta$ treatment VEGF-A protein levels in cell lysates and the conditioned media also significantly increased in a time-dependent manner (Figures 2b and c).

VEGF-A is the antiapoptotic factor in TGF- $\beta /$ Smad3treated vascular SMC-conditioned media. To evaluate whether VEGF-A is the secreted factor that prevents SMC apoptosis, increasing concentrations of VEGF-A were directly applied to cultured vascular SMCs, and UV-induced cell apoptosis was then measured by flow cytometry. Figure 3 a shows that VEGF-A treatment decreased apoptosis in a dose-dependent manner; VEGF-A at $5 \mathrm{ng} / \mathrm{ml}$ was sufficient to significantly inhibit SMC apoptosis. In contrast, either recombinant VEGF-A or VEGF-neutralizing antibody did not influence SMC proliferation (Supplementary Figure S3). Concentrations of VEGF-A were measured using ELISA in TGF- $\beta /$ Smad3-treated vascular SMC-conditioned media. The average level was $3.2 \mathrm{ng} / \mathrm{ml}$ (Supplementary Figure S4). We then evaluated whether VEGF-A is required for the TGF- $\beta$ /Smad3-induced antiapoptotic effect on vascular SMCs. A neutralizing antibody to VEGF-A164 was added to conditioned media taken from TGF- $\beta /$ Smad3-stimulated vascular SMCs that were then applied to naive vascular SMCs. Flow cytometric analysis demonstrated that the neutralizing antibody to VEGF-A abolished the protective effect of conditioned media on vascular SMC survival (Figure 3b). Moreover, small interfering RNA (siRNA) to knockdown VEGF-A in TGF- $\beta$ /Smad3-stimulated vascular SMCs reversed the inhibition of SMC apoptosis produced by conditioned media from TGF- $\beta /$ Smad3-treated cells (Figure 3c). Taken together, these data demonstrate that TGF- $\beta /$ Smad3-stimulated VEGF-A secretion into the conditioned media is necessary and sufficient for protection against SMC apoptosis.

VEGF-A signals by inducing phosphorylation of its cell surface receptor, FLT-1. Our data show increased phosphorylation of FLT-1 (Supplementary Figure S5) as well as altered morphology (compare with Supplementary Figure S6) of naive SMCs after treatment with the conditioned media from TGF- $\beta /$ Smad3-stimulated SMCs. These
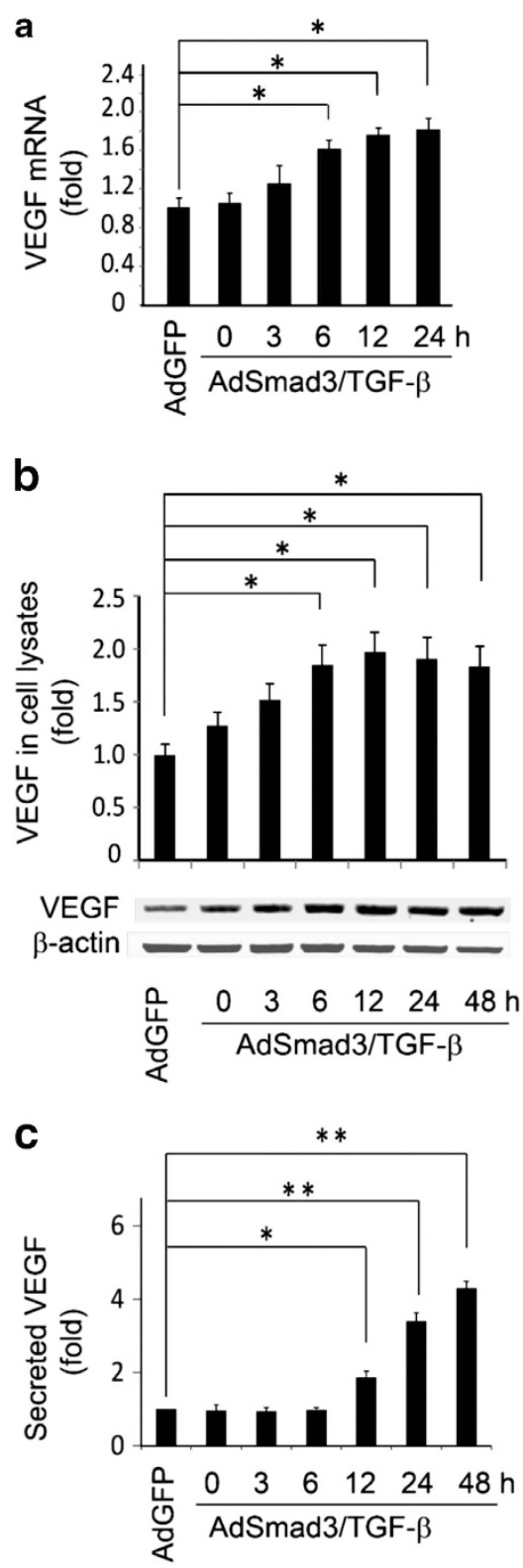

Figure 2 TGF- $\beta /$ Smad3 treatment stimulates VEGF mRNA and protein expression and secretion from rat vascular SMCs. (a) Rat vascular SMCs were infected with either AdGFP or AdSmad3 followed by stimulation with TGF- $\beta(5 \mathrm{ng} /$ $\mathrm{ml})$. Cells were collected at the indicated time points following TGF- $\beta$ stimulation and mRNA levels of VEGF-164 were measured by quantitative RT-PCR. (b) VEGF164 protein levels in cell lysates were measured by western blot analysis and normalized by $\beta$-actin (lower panels show representative western blots). (c) VEGF164 protein levels in the culture media were also measured by enzyme-linked immunosorbent assay (ELISA). Each bar represents mean \pm S.E.M. of three independent experiments $\left({ }^{*} P<0.05\right.$ and ${ }^{*} P<0.01$ compared with the AdGFP control)

results indicate that VEGF-A contained in conditioned media stimulated FLT-1.

Smad3 interacts with HIF-1 $\alpha$ and the resultant complex binds to the VEGF promoter. Previous studies have shown that TGF- $\beta$ regulates VEGF-A production through hypoxia-inducible factor- $1 \alpha$ (HIF-1 $\alpha$ ) in macrophages; ${ }^{27}$ 

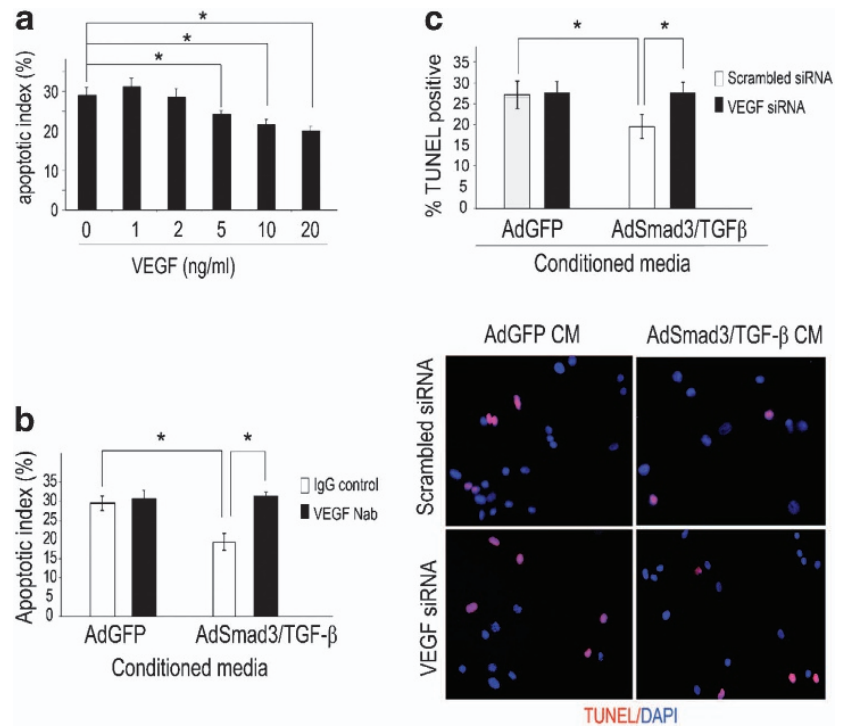

Figure 3 VEGF-164 is the secreted factor that inhibits SMC apoptosis. (a) Effect of recombinant VEGF-164 on SMC apoptosis. Rat aortic SMCs were treated with $1,2,5,10$ or $20 \mathrm{ng} / \mathrm{ml}$ of VEGF for $12 \mathrm{~h}$. The cells were then exposed to UV light for $5 \mathrm{~min}$ and apoptotic index was measured $6 \mathrm{~h}$ later as described in the Materials and Methods ( ${ }^{\star} P<0.05$ compared with solvent control; $n=3$ ). (b) Effect of VEGF neutralization on conditioned media-induced inhibition of SMC apoptosis. Rat aortic SMCs were infected with either AdGFP control or AdSmad3 followed by stimulation with solvent or TGF- $\beta 1(5 \mathrm{ng} / \mathrm{ml})$ for $48 \mathrm{~h}$. Conditioned media were collected and incubated with the VEGF-neutralizing antibody (Nab) or goat IgG $(10 \mu \mathrm{g} / \mathrm{ml})$ for $1 \mathrm{~h}$ before application to naive vascular SMCs for $12 \mathrm{~h}$. The cells were then exposed to UV light for $5 \mathrm{~min}$ and apoptotic index was measured $6 \mathrm{~h}$ later $\left({ }^{*} P<0.05 ; n=3\right)$. (c) Effect of VEGF siRNA on conditioned media-induced inhibition of SMC apoptosis. Rat aortic SMCs were infected with either AdGFP or AdSmad3 followed by stimulation with solvent or TGF- $\beta 1(5 \mathrm{ng} / \mathrm{ml})$ for $48 \mathrm{~h}$ in the presence of scrambled siRNA or VEGF siRNA. Conditioned media were collected and applied to naive vascular SMCs for $12 \mathrm{~h}$. The cells were exposed to UV light for $5 \mathrm{~min}$, fixed $6 \mathrm{~h}$ later and then subjected to TUNEL staining (see representative images) as described in the Materials and Methods, ${ }^{*} P<0.05 ; n=3$

Figure 4 Smad3 interacts with HIF- $1 \alpha$ and bind to the VEGF promoter. (a) Immunoprecipitation of the Smad3/HIF-1 $\alpha$ complex. Rat vascular SMCs were infected with either AdGFP or AdSmad3 followed by stimulation with TGF- $\beta$ $(5 \mathrm{ng} / \mathrm{ml})$ for $6 \mathrm{~h}$. Immunoprecipitation (IP) was then performed as described in the Materials and Methods; IgG was used for control. Immunoprecipitated complexes were detected by western blotting (WB) using antibodies against HIF-1 $\alpha$ or phosphorylated Smad3. Shown is a representative blot from three independent experiments. (b) Proximal ligation assay showing interaction of HIF-1 $\alpha$ and Smad3 in SMCs. Rat vascular SMCs were infected with either AdGFP or AdSmad3 followed by treatment with solvent or TGF- $\beta(5 \mathrm{ng} / \mathrm{ml})$ respectively for $6 \mathrm{~h}$. The cells were then fixed and the interaction between Smad3 and HIF-1 $\alpha$ was detected by Proximity Ligation Assay (red punctate marked by arrows) as described in the Materials and Methods. Shown are representative images each from three independent experiments; the lower panel shows enlarged nuclei (blue, DAPI stained). Scale bar is $5 \mu \mathrm{m}$. (c and d) Quantification of Smad3-HIF-1 $\alpha$ interaction in SMCs. Proximal ligation was quantified as the number of ligation-positive punctate (red, see b) per cell (c) or per nucleus (d). ( ${ }^{*} P<0.05$ compared with AdGFP control; $n=3$ ). (e) Rat vascular SMCs were infected with either AdSmad3 or AdGFP and then treated with TGF- $\beta(5 \mathrm{ng} / \mathrm{ml})$ for $6 \mathrm{~h}$. Cells were crosslinked to fix the interaction between protein and DNA. The cell lysates were then sonicated to yield small DNA fragments between 200 and $700 \mathrm{bp}$. The samples were then incubated with Smad3, HIF- $1 \alpha$ antibodies or control IgG. DNA bound to Smad3 or HIF- $1 \alpha$ were recognized by antibodies and precipitated by protein $\mathrm{A} / \mathrm{G}$ agarose beads. The precipitated DNA was measured by quantitative PCR using primer pairs to proximal or distal region of VEGF promoter. ( ${ }^{*} P<0.05$ compared with IgG control; $n=3$ ) however, the mechanism of TGF- $\beta /$ Smad3-regulated VEGFA expression in SMCs has not been explored. We tested the hypothesis that Smad3 and HIF-1 $\alpha$, both transcription factors, synergistically regulate VEGF-A gene transcription in vascular SMCs (Figure 4).

To determine whether Smad3 interacts with $\mathrm{HIF}-1 \alpha$, immunoprecipitation was performed and the formation of a Smad3/HIF- $1 \alpha$ complex was assessed by measuring immmunoprecipitated Smad3 or HIF-1 $\alpha$ through western blotting. At baseline, there was an association between Smad3 and HIF-1 $\alpha$; upregulation of Smad3 and stimulation with TGF- $\beta$ significantly increased the interaction between these two proteins (Figure 4a). The results demonstrate that HIF- $1 \alpha$ and Smad3 physically interact, and TGF- $\beta$ stimulation enhances this interaction (Figure 4a). To confirm the Smad3/HIF-1 $\alpha$ interaction, vascular SMCs were infected with AdSmad3 or AdGFP followed by stimulation with TGF- $\beta$ or solvent, and then incubated with antibodies to Smad3 and HIF- $1 \alpha$.

a Treatment: AdGFP AdSmad3/TGF- $\beta$

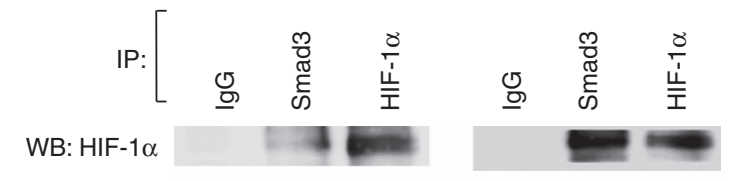

WB: p-Smad3
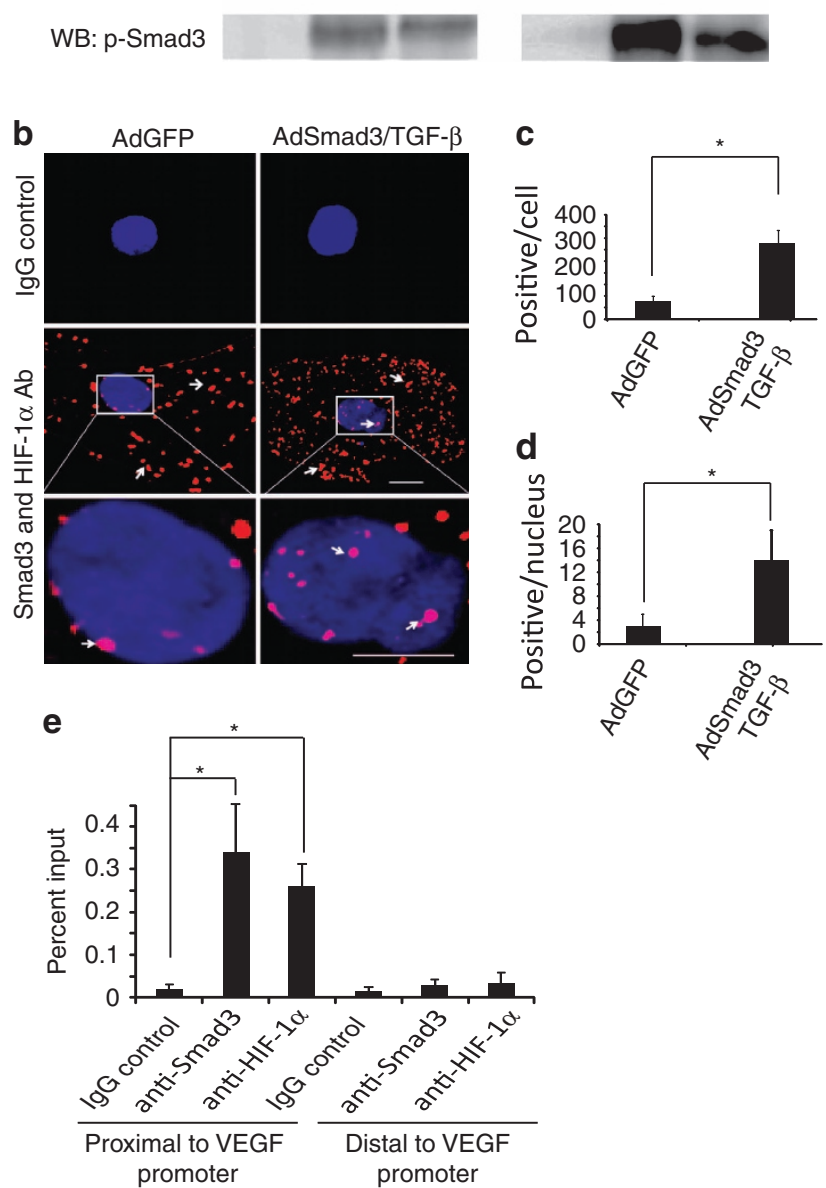
Fluorescent amplification products (red dots) within SMCs showed that Smad3 and HIF-1 $\alpha$ indeed interacted (Figure 4b). The quantitative results show that there was a basal level of Smad3 and HIF-1 $\alpha$ interaction before TGF- $\beta /$ Smad3 treatment, and this interaction was significantly increased by the upregulation of Smad3 and treatment with TGF- $\beta$ (Figure 4c). TGF- $\beta /$ Smad3 treatment also significantly increased nuclear translocation of this Smad3-HIF-1 $\alpha$ complex (Figure $4 d$ ). These results demonstrate that TGF- $\beta / \mathrm{Smad} 3$ treatment enhances the interaction between Smad3 and HIF-1 $\alpha$ in SMCs. In order to explore the possibility that simultaneous increases in both Smad3 and HIF1 $\alpha$ synergistically enhance the expression of VEGF-A, we determined whether levels of HIF $1 \alpha$ were increased following stimulation of SMCs with TGF- $\beta /$ Smad3. RT-PCR revealed that at several time points following TGF- $\beta /$ Smad3 stimulation, HIF $1 \alpha$ expression did not change (Supplementary Figure S7).

We then performed chromatin immunoprecipitation (ChIP) studies to evaluate whether Smad3 or HIF-1 $\alpha$ bind to VEGF-A promoter. Vascular SMCs were infected with either AdSmad3 or AdGFP and then treated with TGF- $\beta(5 \mathrm{ng} / \mathrm{ml})$ for $6 \mathrm{~h}$. Cells were crosslinked to stabilize the interaction between protein and DNA. The cell lysates were sonicated to yield small DNA fragments between 200 and $700 \mathrm{bp}$. The samples were then incubated with anti-Smad3 or anti-HIF-1 $\alpha$ antibodies or control IgG. Smad3 and HIF-1 $\alpha$ bound to DNA fragments were detected by their respective antibody and precipitated by protein $A / G$ agarose beads. The precipitated DNA was measured by quantitative PCR using primer pairs proximal or distal to VEGF-A promoter. The results (Figure 4e) indicate that Smad3 and HIF-1 $\alpha$ specifically bind to chromatin in the proximal region of VEGF-A promoter.

Increased VEGF-A expression accompanies Smad3 elevation after arterial balloon angioplasty. In the foregoing in vitro experiments, we have established that elevated TGF- $\beta /$ Smad3 inhibit SMC apoptosis by upregulating the production of VEGF-A that functions through an autocrine mechanism to inhibit SMC apoptosis (Figures 1-3). We further investigated whether TGF- $\beta /$ Smad3 regulate $\mathrm{IH}$ through this mechanism using the balloon-injured carotid artery as a model. Male Sprague-Dawley rats underwent sham surgery $(n=4)$ or balloon angioplasty followed by infusion of $200 \mu \mathrm{l}$ AdSmad3 $(n=4)$ or AdGFP $(n=4)$ $\left(2.5 \times 10^{9}\right.$ plaque-forming units (PFUs) $/ \mathrm{ml}$ ) over $20 \mathrm{~min}$. Animals were killed at 3 or 7 days after surgery. VEGF-Aimmunostained tissue sections revealed that VEGF-A expression was remarkably low in the uninjured artery (Figures $5 a$ and d). However, VEGF-A expression increased in the media 3 days after vascular injury (Figure $5 b$ ), and further increased in the media and neointima 7 days after injury (Figure 5c). VEGF-A levels were further enhanced at 3 and 7 days in injured arteries treated with AdSmad3 (Figure 5, compare Figure e with $b$ and Figure $f$ with $c$ and see the quantification in Figure g). To quantify levels of gene expression, injured carotid arteries were harvested and analyzed for Smad3 and VEGF-A mRNA by quantitative RT-PCR (Figures $5 \mathrm{~h}$ and i). Our results show that both VEGF-A and Smad3 mRNA levels were elevated 3 days and 7 days after vascular injury in AdGFP-treated control
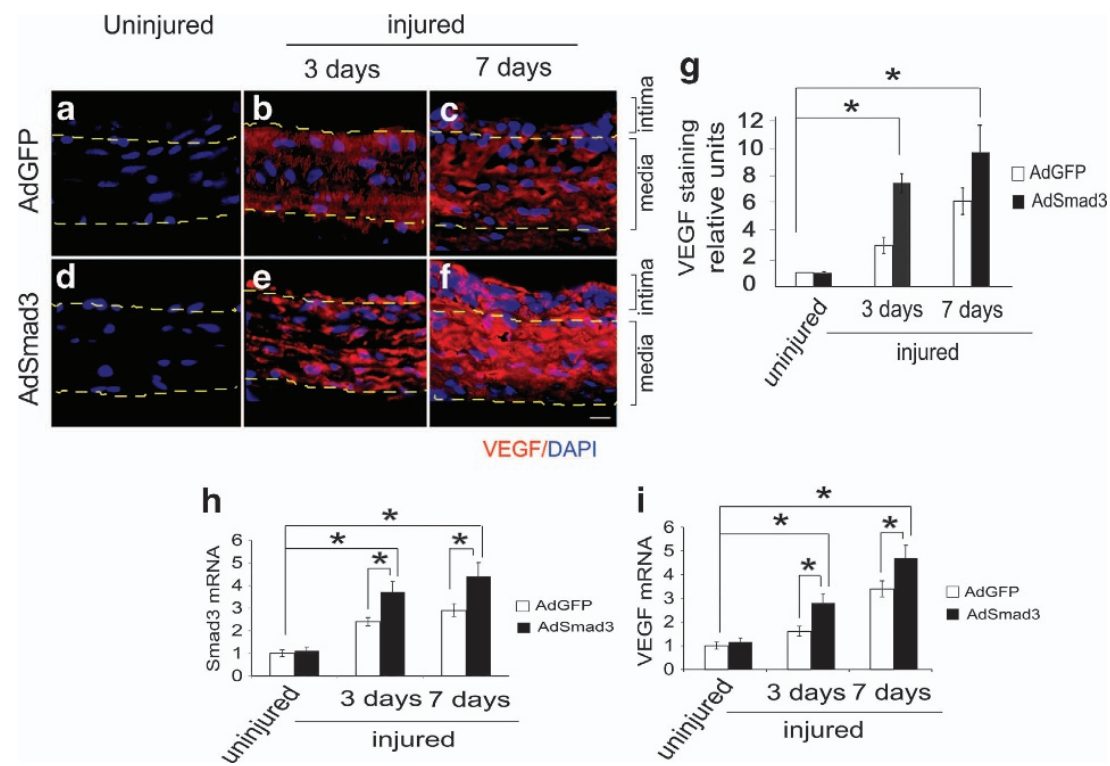

Figure 5 Smad3 stimulates VEGF expression in balloon-injured rat carotid arteries. (a-f) Effect of Smad3 up-regulation on VEGF expression in balloon-injured rat carotid arteries. Sham surgery ( $\mathbf{a}$ and $\mathbf{d}$ ) or balloon angioplasty (b, c, e and f) was performed in rat common carotid arteries followed by infusion $\left(200 \mu \mathrm{l}\right.$ virus, $\left.2.5 \times 10^{9} \mathrm{PFU} / \mathrm{ml}\right)$ of AdGFP or AdSmad3 for 20 min. Arteries were retrieved 3 days ( $\mathbf{b}$ and $\mathbf{e}$ ) or 7 days ( $\mathbf{c}$ and $\mathbf{f}$ ) after injury and immunostaining of VEGF-164 (red) was performed on carotid sections as described in the Materials and Methods. Shown are representative images from a total of four animals. Dashed lines define the media layer. ( $g$ ) Quantification of protein expression levels of VEGF in experiments (a-f) based on relative fluorescence intensity $\left(n=4 ;{ }^{*} P<0.05\right.$ compared between injured and uninjured arteries). (h and $\mathrm{i}$ ) Quantification of mRNA levels of Smad3 (h) and VEGF (i) in rat carotid arteries. In parallel to experiments (a-f), rat carotid arteries at 3 and 7 days were homogenized for mRNA extraction and RT-PCR was used to quantify levels of Smad3 and VEGF-164 (shown in $\mathbf{h}$ and $\mathbf{i}$, respectively). Each bar represents mean \pm S.E.M. of four animals $\left({ }^{*} P<0.05\right.$ compared between injured and uninjured arteries, or without and with Smad3 overexpression) 
animals, and upregulation of Smad3 further increased VEGF-A expression (Figures $5 \mathrm{~h}$ and i).

Smad3 upregulation reduces cell apoptosis in the arterial wall after balloon injury. To test whether Smad3 gene transfer decreases apoptosis in vivo, TUNEL staining was performed on sections adjacent to those used for VEGF staining that were prepared from carotid arteries infected with AdSmad3 or AdGFP control after angioplasty. TUNELpositive apoptotic cells were rarely seen in uninjured artery (Figure 6a). However, apoptosis was significantly increased after carotid injury (Figures $6 a$ and b). Similar to the in vitro results, AdSmad3-infused animals had a significant decrease in the number of TUNEL-positive cells compared with GFP controls following arterial injury (Figure $6 \mathrm{c}$ ). To confirm these findings, we performed additional studies that show that AdSmad3 treatment increased VEGF but decreased apoptosis as indicated by reduced active (cleaved) Caspase-3 that was localized on the sections adjacent to those stained positive for VEGF (Supplementary Figure S8). Moreover, reducing Smad3 activity by perivascular application of a specific Smad3 inhibitor, SIS3, significantly increased the number of TUNEL-positive cells (Figures $6 f-h$ ). These results demonstrate that Smad3 upregulation inhibits and downregulation promotes cell apoptosis in the injured artery. To further determine whether VEGF-A is responsible for the decrease of apoptosis induced by Smad3 upregulation, an inhibitor to the VEGF-A receptor (FLT1) was applied to the perivascular tissue following AdGFP or AdSmad3 intraluminal infusion into balloon-injured arteries. Our data show that this inhibitor (Axitinib) abrogated the inhibitory effect of Smad3 overexpression on SMC apoptosis (Figures $6 \mathrm{~d}$ and $\mathrm{e}$ ) and also reduced $\mathrm{IH}$ (the intima/media area ratio, see Supplementary Figure S9).

Taken together, our results obtained from both in vitro and in vivo studies reveal that elevated TGF- $\beta /$ Smad3 signaling stimulates VEGF-A production that in turn suppresses SMC apoptosis through an autocrine mechanism.

\section{Discussion}

We have identified a novel pathway through which TGF- $\beta$ in the presence of elevated Smad3 inhibits SMC apoptosis through an autocrine signaling pathway involving VEGF-A. Moreover, our in vivo data suggest that this mechanism of TGF- $\beta /$ Smad3-mediated, VEGF inhibition of apoptosis also occurs in arteries following angioplasty and may play an important role in the development of $\mathrm{IH}$. Persuasive evidence

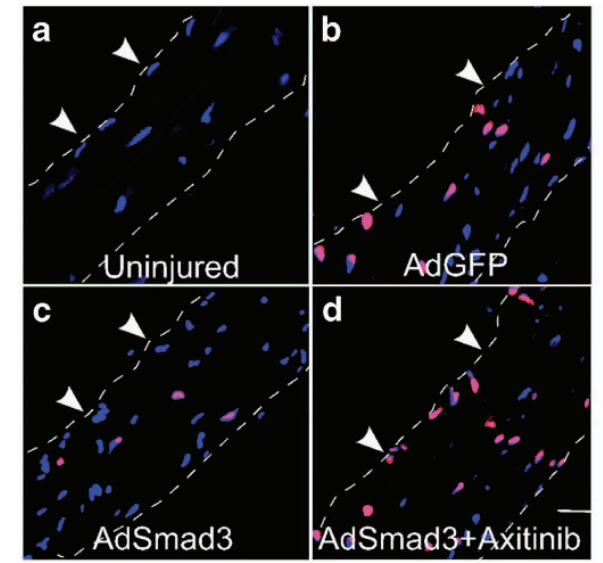

TUNEL/DAPI

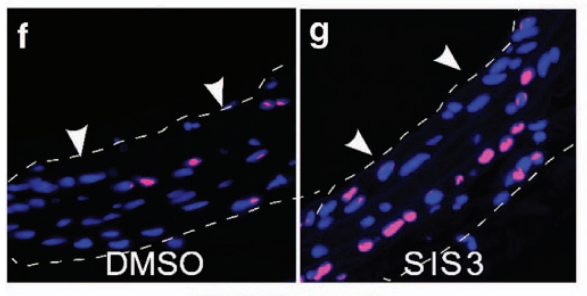

TUNEL/DAPI

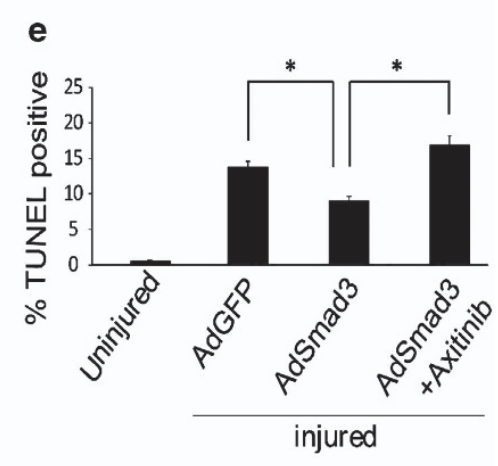

h

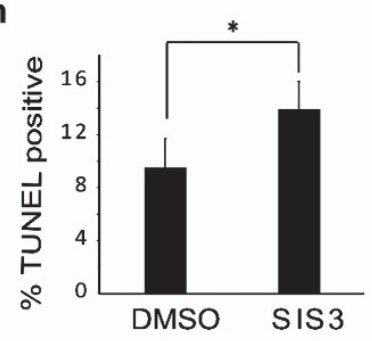

Figure 6 Inhibition of VEGF receptor or Smad3 reverses the antiapoptotic effect of Smad3 in balloon-injured rat carotid arteries. Sham surgery (a) or balloon angioplasty (b-d) was performed in rat common carotid arteries followed by infusion ( $200 \mu \mathrm{l}$ virus, $2.5 \times 10^{9}$ PFUs/ml) of AdGFP (b) or AdSmad3 in the absence (c) or presence of 1 mg of Axitinib (d). Arteries were retrieved 3 days after injury and TUNEL assay (red) was performed on carotid sections as described in the Materials and Methods. Shown in (a-d) are representative images each from four animals; dashed lines define the media layer; arrowheads mark internal elastic lamina (IEL). (e) Quantification of percent TUNEL-positive cells (versus total cells). Each bar represents mean \pm S.E.M. of four animals ( ${ }^{*}<0.05$ compared between AdGFP and AdSmad3, or without and with Axitinib). In order to determine the effect of inhibition of Smad3 on apoptosis, immediately following balloon angioplasty, $100 \mu \mathrm{g}$ of SIS3 (Smad3 inhibitor, Sigma-Aldrich) or vehicle control (DMSO) dissolved in $300 \mu$ of pluronic gel was applied around the injured artery. Cross-sections were collected 14 days after surgery and TUNEL assay (red) was performed. (f and $\mathbf{g}$ ) Representative images of (f) vehicle control and (g) SIS3 treatment, respectively, each from three animals. (h) Quantification of percent TUNEL-positive cells (versus total cells). Each bar represents mean \pm S.E.M. of three animals $\left({ }^{*} P<0.05\right)$ 
includes the following: from day 3 to 7 post angioplasty, Smad3 levels progressively increase in parallel with VEGF in SMCs of the arterial media (Figure 5). Moreover, viral expression of Smad3 in injured arteries further enhances VEGF expression and is accompanied by a decrease in the number of apoptotic cells and an increase in $\mathrm{IH}$, whereas inhibiting Smad3 in injured arteries with SIS3 increased the number of apoptotic cells (Figure 6). Supporting a specific role for VEGF in the inhibition of apoptosis, treatment following angioplasty with Axitinib, a VEGF inhibitor, reversed the antiapoptotic effects of Smad3 (Figure 6). Thus, our data suggest that TGF- $\beta$ and Smad3 stimulate the secretion of VEGF from vascular SMCs after angioplasty that in turn contributes to the growth of the neointima by reducing the number of apoptotic cells. While in our previous studies we have explored how TGF- $\beta /$ Smad3 promote IH by stimulating SMC proliferation, the findings from our current study are novel in that we show that TGF- $\beta /$ Smad3 also contributes to $\mathrm{IH}$ by suppressing SMC apoptosis. Our results not only produce new insights into the mechanism of angioplastyinduced $\mathrm{IH}$, but they also provide a further explanation of the long-standing conundrum of why TGF- $\beta$ stimulates apoptosis in vitro but is a potent stimulant of $\mathrm{IH}$ in vivo.

The in vitro effects of TGF- $\beta$ are well known. In SMCs this cytokine suppresses proliferation as well as migration and promotes apoptosis. ${ }^{28-30}$ One would then logically predict that TGF- $\beta$ would be a potent inhibitor of angioplasty-induced IH that is the consequence of SMC proliferation and migration and is diminished by SMC apoptosis. ${ }^{31,32}$ Many studies have demonstrated that TGF- $\beta$ is upregulated in arteries following angioplasty or vascular intervention. However, this cytokine consistently stimulates rather than inhibits $\mathrm{IH}^{33}$ Our group has made progress in deciphering this paradox. Our previous in vitro studies revealed that in the presence of elevated Smad3, TGF- $\beta$ was transformed from an inhibitor into a stimulant of SMC proliferation. ${ }^{2}$ Moreover, there are compelling data revealing that levels of Smad3 are elevated in vivo consequent to vascular reconstruction or angioplasty. In rat carotid arteries following angioplasty, we have found that levels of Smad3 increase in the media by day 3 and peak in the media and neointima by day $14 .^{2}$ In addition, we have previously shown that our findings in animals are translatable to human disease. We have observed that Smad3 in conjugation with cell proliferation is upregulated in human restenotic disease but not in primary atherosclerotic lesions. ${ }^{26}$ We (and others) have also demonstrated in vivo that following gene transfer of Smad3, TGF- $\beta$ enhances SMC proliferation as well as $\mathrm{IH}$, whereas reducing Smad3 inhibits $\mathrm{IH}^{2,34,35}$

The role of SMC apoptosis in $\mathrm{IH}$ is somewhat complex. In response to arterial injury, apoptosis occurs typically in two phases. As observed in a mouse model of transluminal arterial injury, apoptosis increased rapidly immediately after injury and peaked at $24 \mathrm{~h}$, and then decreased but persisted through 14 days. $^{36}$ It is believed that in the early stage after injury, apoptotic cells release growth factors and cytokines, stimulating SMC proliferation. Thus, early apoptosis after vascular injury may contribute to $\mathrm{IH}^{37}$ In later stages, however, apoptosis reduces SMC numbers in the arterial wall, thereby inhibiting $\mathrm{IH}$. We observed that following balloon injury of rat carotid arteries, VEGF levels markedly increased after 3 days
(Figure 5), suggesting that elevation of VEGF in response to injury likely contributes to $\mathrm{IH}$ by suppressing later-stage apoptosis. In support of this proposition, compelling data from multiple reports reveal that the induction of apoptosis by various methods reduces $\mathrm{IH}$ in animal models. ${ }^{4-7}$ As apoptosis that develops following angioplasty has the potential to mitigate the development of $\mathrm{IH}$, our findings then offer a new mechanism through which TGF- $\beta$ might exacerbate restenosis by inhibiting apoptosis. Thus TGF- $\beta$, by both blocking SMC apoptosis and by promoting proliferation, is a potent initiator of events that lead to $\mathrm{IH}$. Evidence indicates that apoptosis and proliferation, although different processes, are interrelated. We therefore evaluated whether VEGF-A produced by TGF- $\beta /$ Smad3 might enhance SMC proliferation in addition to influencing apoptosis. Interestingly, neither recombinant VEGF-A nor FLT-1-neutralizing antibody affected SMC proliferation (Supplementary Figure S3), suggesting that the effect of VEGF-A is confined to inhibiting apoptosis and does not involve an effect on SMC proliferation.

The role of VEGF-A in the formation of $\mathrm{IH}$ remains controversial. Initial reports using plasmid-mediated gene transfer suggested that VEGF-A expression facilitated reendothelialization and inhibited $\mathrm{IH}$ following angioplasty. ${ }^{38}$ Alternatively, later studies with VEGF-A protein and gene transfer revealed that VEGF-A treatment increased $\mathrm{IH}$ in a rabbit carotid artery injury model, ${ }^{39,40}$ whereas inhibition of VEGF-A through the application of a soluble VEGF receptor (sFLT-1) attenuated $\mathrm{IH}^{41,42}$ This protein has been tested in clinical trials where it was found to have no significant effect on restenosis. ${ }^{43}$ Adding to the uncertainty of VEGF's role in $\mathrm{IH}$, low levels of VEGF-A have been found to promote proliferation of endothelial cells, whereas it has been reported that VEGF-A can induce endothelial cell apoptosis in the presence of elevated TGF- $\beta .^{44}$ These results collectively indicate that the role of VEGF-A in IH is complex. Our data provide a possible explanation for this complexity. The arterial wall contains multiple cell types and with the injury that accompanies angioplasty or vascular reconstruction, these cells are altered by multiple cytokines and growth factors. The consequence may be competing effects with regard to the development of IH. Specifically, VEGF-A is capable of promoting EC regeneration that prevents thrombosis and suppresses underlying $\mathrm{IH}$. However, our data demonstrate that VEGF-A also prevents apoptosis of SMCs and promotes $\mathrm{IH}$. Considering these two opposing effects of VEGF-A, it may not be surprising that the efforts to eliminate restenosis by directly targeting VEGF have thus far generated confounding results. As such, one might conceive of a strategy whereby arteries following angioplasty are treated simultaneously with VEGF as well as an inhibitor of Smad3 upregulation. This combination would preserve the beneficial effect of VEGF on ECs but abrogate its detrimental effect on SMC apoptosis. This strategy would be viable presuming that the effect of VEGF on endothelial cells is Smad3 independent. We and others have already demonstrated that Smad3 has an independent stimulatory effect on $\mathrm{IH}^{2,34}$

Following our discovery that TGF- $\beta /$ Smad3 stimulate the secretion of VEGF-A from vascular SMCs, we further explored the pathways through which TGF- $\beta$ promotes VEGF production. It is known that $\mathrm{HIF}-1 \alpha$ is a crucial transcription 
factor regulating VEGF-A production in the context of hypoxia. Moreover, it has been found that HIF- $1 \alpha$ and Smad2/3 interact in cancer cell lines leading to VEGF-A production. ${ }^{45}$ How Smad3 regulates VEGF-A expression in SMCs has not been delineated. Our evaluations using both immunoprecipitation and proximity ligation clearly demonstrate a specific interaction between Smad3 and HIF-1 $\alpha$ that appears first in the cytoplasm and then in the nucleus. Subsequent binding of this complex to the VEGF promoter leads to VEGF expression. Thus, we conclude that Smad3 and HIF-1 $\alpha$, both transcription factors, interact and synergistically stimulate VEGF-A expression in SMCs. Moreover, we found that HIF-1 $\alpha$ expression did not change following TGF- $\beta / S$ mad3 treatment (Supplementary Figure S4), confirming that VEGF-A upregulation is because of elevation of Smad3 signaling rather than HIF- $1 \alpha$.

Taken together, our studies suggest a new mechanism through which TGF- $\beta$ promotes the development of $\mathrm{IH}$ (Figure 7). Following the arterial injury that accompanies angioplasty, levels of TGF- $\beta$ and Smad3 are both elevated. TGF- $\beta$ then stimulates SMCs and through a mechanism that involves Smad3 and HIF-1 $\alpha$, VEGF-A is produced and secreted. Through an autocrine pathway, secreted VEGF-A in turn binds to and activates FLT-1 receptors on SMCs, thereby reducing SMC apoptosis. This mechanism provides a new perspective for understanding why TGF- $\beta$ has disparate functions in vitro and in vivo. Whereas TGF- $\beta$, in the presence of basal levels of Smad3, has a proapoptotic effect on SMCs in culture, TGF- $\beta$ following arterial injury, in the presence of elevated Smad3, is transformed into a factor that inhibits SMC apoptosis, promotes cell survival and therefore contributes to the development of $\mathrm{IH}$.

Importantly, our previous studies show significantly more Smad3 expression in restenotic lesions compared with primary atheromata in patients, ${ }^{26}$ making Smad3 a relevant target in the treatment of human restenotic disease. Thus, this novel pathway of TGF- $\beta /$ Smad3-mediated suppression of SMC apoptosis may inspire new strategies for future therapeutic interventions to effectively attenuate $\mathrm{IH}$ and prevent restenosis.

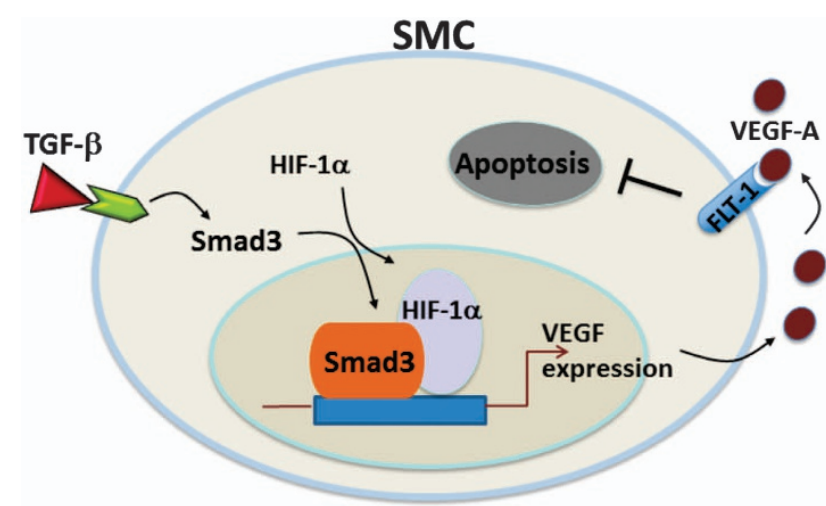

Figure 7 Schematic of TGF- $\beta /$ Smad3-initiated inhibition of SMC apoptosis through a VEGF pathway. TGF- $\beta$ activates the TGF- $\beta$ receptor that in turn activates Smad3. Phospho-Smad3 translocates into the nucleus, and by interacting with HIF$1 \alpha$ upregulates the gene expression of VEGF-A. Secreted VEGF-A binds to its receptor, FLT-1, and activates the VEGF-FLT-1 pathway, thus inhibiting SMC apoptosis

\section{Materials and Methods}

Animals. The experiments involving animal use were carried out in strict accordance with the recommendations in the Guide for the Care and Use of Laboratory Animals of the National Institutes of Health. The protocol (Permit Number: M02273) was approved by the Institutional Animal Care and Use Committee (IACUC) of the University of Wisconsin-Madison. All surgeries were performed under isoflurane anesthesia (through inhaling, flow rate $2 \mathrm{ml} / \mathrm{min}$ ), and all efforts were made to minimize suffering. Animals were killed in a chamber gradually filled with $\mathrm{CO}_{2}$.

Reagents. Recombinant TGF- $\beta$, VEGF-A and the anti-VEGF-A-neutralizing antibody were from R\&D Systems (Minneapolis, MN, USA). Dulbecco's modified Eagle's medium (DMEM) and cell culture reagents were from Invitrogen (Carlsbad, CA, USA). All the other reagents were from Sigma (St. Louis, MO, USA) unless otherwise specified.

Smooth muscle cell culture. Rat aortic vascular SMCs were isolated from the thoracoabdominal aorta of male Sprague-Dawley rats. Vascular SMCs were used at passages 5 to 7 for all experiments and were maintained in DMEM supplemented with $10 \%$ fetal bovine solution (FBS) at $37^{\circ} \mathrm{C}$ with $5 \% \mathrm{CO}_{2}$. Cells were starved in DMEM containing $0.5 \%$ FBS for $24 \mathrm{~h}$, and then treated with recombinant TGF- $\beta(5 \mathrm{ng} / \mathrm{ml})$ or equal volume of solvent $(4 \mu \mathrm{M} \mathrm{HCl}$ and $1 \mu \mathrm{g} / \mathrm{ml}$ BSA final) for $48 \mathrm{~h}$.

Construction of adenoviral vectors and infection of SMCs. AdSmad3 and AdGFP were constructed as previously described. AdGFP was used as a control. Vascular SMCs were infected with adenovirus $\left(3 \times 10^{4}\right.$ particles/cell) in DMEM containing $2 \%$ FBS for $4 \mathrm{~h}$, and the medium was then changed to fresh DMEM containing $10 \%$ FBS.

Induction and determination of vascular SMC apoptosis in vitro. We used an established method with minor modifications to induce SMC apoptosis. ${ }^{46}$ SMCs were infected with AdGFP (control) or AdSmad3 followed by treatment with solvent or TGF- $\beta$ for $24 \mathrm{~h}$. For some experiments, naive SMCs were treated with conditioned media or recombinant VEGF. Then, SMCs were changed to serum-free medium for $4 \mathrm{~h}$ to synchronize cells. The culture media were then changed back to DMEM with $10 \%$ serum for $2 \mathrm{~h}$ and exposed to UV light for $5 \mathrm{~min}$. After $6 \mathrm{~h}$ of continued incubation, cells were harvested and resuspended in binding buffer (10 mM HEPES, pH 7.4, $140 \mathrm{mM} \mathrm{NaCl}$ and $2.5 \mathrm{mM}$ $\mathrm{CaCl}_{2}$ ) with $20 \mu$ of phycoerythrin (PE)-conjugated Annexin-V protein (Annexin-V$\mathrm{PE}, 10 \mu \mathrm{g} / \mathrm{ml}$ ) followed by $20 \mu \mathrm{l}$ of 7-amino-actinomycin (7-AAD; $50 \mu \mathrm{g} / \mathrm{ml})$. After $15 \mathrm{~min}$ of incubation at room temperature in the dark, $400 \mu \mathrm{l}$ of binding buffer was added to stop the reaction. Apoptotic cells were assessed by binding of Annexin-V (PE) along with 7-AAD exclusion to confirm the integrity of the cell membrane. Annexin-V-stained vascular SMCs were analyzed with a FACSCalibur (BD Biosciences, San Jose, CA, USA). Data acquisition was performed with the CellQuest software package (BD Biosciences) and analysis was performed with the FlowJo software (TreeStar Inc., Ashland, OR, USA). The specificity of Annexin- $V$ binding to vascular SMCs was verified by a negative control in the presence of $5 \mathrm{mM}$ EDTA.

Enzyme-linked immunosorbent assay. ELISA was used to detect secreted VEGF-A in vascular SMC culture media using a VEGF ELISA kit based on the sandwich enzyme immunoassay technique (R\&D Systems, Minneapolis, MN, USA). The absorbance was determined using a Flex Station 3 microplate reader (Molecular Devices, Sunnyvale, CA, USA).

Western blotting analysis. Cells were lysed in RIPA buffer containing protease inhibitors $(50 \mathrm{mM}$ Tris, $150 \mathrm{mM} \mathrm{NaCl}, 1 \%$ Nonidet P-40, $0.1 \%$ sodium dodecyl sulfate and $10 \mu \mathrm{g} / \mathrm{ml}$ aprotinin). Protein concentration was determined by Bio-Rad DC Protein Assay kit (Hercules, CA, USA). From each sample, $30 \mu \mathrm{g}$ of protein was separated by $10 \%$ SDS-PAGE and transferred to nitrocellulose membranes. Protein levels were assessed by immunoblotting with the following antibodies: rabbit anti-VEGF (Santa Cruz Biotechnology, Santa Cruz, CA, USA), rabbit anti-phospho-Smad3 (Cell Signaling, Boston, MA, USA) and mouse anti- $\beta$-actin (Sigma). After incubation with appropriate primary and horseradish peroxidase-conjugated secondary antibodies, the specific protein bands on the membranes were visualized by using enhanced chemiluminescence reagents (Pierce, Davenport, IL, USA). 
Immunoprecipitation. Briefly, cells were lysed in Nonidet P-40 buffer. Protein A-Sepharose beads (Santa Cruz Biotechnology) and $5 \mu \mathrm{g}$ of primary antibody or control rabbit IgG was added to lysates and incubated at $4^{\circ} \mathrm{C}$ with constant rotation for $12 \mathrm{~h}$. Following centrifugation, pelleted beads were washed five times with Nonidet P-40 buffer. The final pellets were resuspended in $20 \mu \mathrm{l}$ of sample buffer and heated to $100^{\circ} \mathrm{C}$ for $5 \mathrm{~min}$. Immunoprecipitated proteins were then separated on $10 \%$ SDS-PAGE, transferred to nitrocellulose membranes and detected by immunoblotting with the following primary antibodies: mouse anti-HIF-1 $\alpha$, rabbit anti-p-Smad3 and rabbit anti-Smad3 (Cell Signaling).

Proximity ligation assay to assess the interaction between Smad3 and HIF-1 $\alpha$. Vascular SMCs were infected with AdSmad3 or control virus (AdGFP) followed by stimulation with TGF- $\beta(5 \mathrm{ng} / \mathrm{ml})$ or solvent control for $6 \mathrm{~h}$. The cells were fixed in $4 \%$ paraformaldehyde at room temperature for $10 \mathrm{~min}$. The interaction between Smad3 and HIF-1 $\alpha$ proximity was detected by Proximity Ligation Assay (OLINK, Uppsala, Sweden)

Principles: Primary antibodies were mouse anti-HIF- $1 \alpha$ (Novus Biologicals, Littleton, CO, USA) and rabbit anti-Smad3 (Abcam, Cambridge, MA, USA) to recognize the target antigens. Mouse and rabbit species-specific secondary antibodies with a unique short DNA strand attached bind to anti-Smad3 and antiHIF- $1 \alpha$ antibodies, respectively. When these two DNA probes are in close proximity, the DNA can interact through a subsequent addition of two other circleforming DNA oligonucleotides. After enzymatic ligation, the DNA was amplified using a polymerase. The resulting high concentration of fluorescence amplification product is visualized with a fluorescence microscope.

Chromatin immunoprecipitation. Vascular SMCs were infected with either AdSmad3 or AdGFP and then treated with TGF- $\beta(5 \mathrm{ng} / \mathrm{ml})$ for $6 \mathrm{~h}$. Cells were crosslinked with $1 \%$ formaldehyde for $15 \mathrm{~min}$ at RT, after which $125 \mathrm{mM}$ glycine was added to quench the formaldehyde. The cells were then lysed in $500 \mu \mathrm{l}$ lysis buffer supplemented with protease inhibitor cocktail (Roche Diagnostics, Basel, Switzerland). Nuclei were pelleted at $3000 \times g$ for $5 \mathrm{~min}$ at $4{ }^{\circ} \mathrm{C}$ and resuspended in $400 \mu \mathrm{l}$ of nuclear lysis buffer. The samples were sonicated to yield sheared DNA fragments between 200 and $700 \mathrm{bp}$ and lysates were cleared by centrifugation. The samples were then incubated with $2.5 \mu \mathrm{g}$ of Smad3 antibody, $2.5 \mu \mathrm{g}$ of HIF-1 $\alpha$ antibody or control IgG (Upstate/Millipore, Billerica, MA, USA) for $1 \mathrm{~h}$ at $4^{\circ} \mathrm{C}$. To reduce nonspecific association, $30 \mu \mathrm{g}$ of sonicated salmon sperm DNA and $50 \mu \mathrm{g}$ of BSA (Promega, Madison, WI, USA) were added to each sample.

Immunoprecipitation (IP) was carried out using $50 \mu \mathrm{l}$ of $50 \%(\mathrm{v} / \mathrm{v})$ Protein A/G PLUS-Agarose beads (Santa Cruz) at $4^{\circ} \mathrm{C}$ overnight. The immune complexes were washed sequentially with low-salt wash buffer, high-salt buffer, LiCl wash buffer and TE buffer. The DNA-protein complexes were eluted with $200 \mu$ l elution buffer $(1.5 \%$ SDS in $50 \mathrm{mM}$ NaHCO3). The samples were incubated at $65^{\circ} \mathrm{C}$ overnight to reverse formaldehyde crosslinks, and phenol-chloroform extracted and ethanol precipitated. The resultant purified DNA was dissolved in $20 \mu \mathrm{l}$ of $10 \mathrm{mM}$ Tris- $\mathrm{HCl}, \mathrm{pH} 8.5$, for further analysis.

Immunocytochemistry of vascular SMCs. Vascular SMCs were seeded at $50-60 \%$ confluence in DMEM medium in chambered slides (BD Biosciences) and incubated for $24 \mathrm{~h}$. The cells were then infected with AdSmad3 or AdGFP and then treated with recombinant TGF- $\beta(5 \mathrm{ng} / \mathrm{ml})$ or solvent for $72 \mathrm{~h}$. Conditioned media from AdGFP-treated or AdSmad3/TGF- $\beta$-treated SMCs were collected and incubated with $10 \mu \mathrm{g} / \mathrm{ml}$ VEGF-A-neutralizing antibody (Nab) or normal goat IgG for $1 \mathrm{~h}$. The antibody-treated conditioned media were then added to naive SMCs and incubated for $30 \mathrm{~min}$. Cells were fixed in $4 \%$ paraformaldehyde at room temperature for $10 \mathrm{~min}$ and permeabilized with $0.2 \%$ Triton $\mathrm{X}-100$. Immunostaining for injured rat carotid arteries with or without Smad3 overexpression was performed as described previously.

Rat balloon injury model and in vivo gene delivery. Male SpragueDawley rats $(\sim 350 \mathrm{~g})$ underwent balloon injury of the left common carotid artery as described previously. Briefly, after induction of anesthesia with isofluorane, a 2-French balloon catheter (Edwards Lifesciences, Irvine, CA, USA) was inserted through the left external carotid artery into the common carotid and insufflated with $2 \mathrm{~atm}$ of pressure three times. After injury, animals received intraluminal administration of adenoviral vectors $\left(2.5 \times 10^{9}\right.$ PFUs in $200 \mu$ of PBS over
$20 \mathrm{~min})$. The external carotid artery was then ligated, and flow was re-established through the common carotid and internal carotid arteries. In a group of rats, a chemical inhibitor of VEGF receptor (Axitinib, $3 \mathrm{mg}$ ) was dissolved in $300 \mu \mathrm{l}$ of pluronic gel and applied periadventitially immediately after vascular injury. Rats were killed 3 or 7 days after injury. Half the artery was processed for mRNA analysis and the other half fixed in $4 \%$ paraformaldehyde overnight for cryopreservation in Optimal Cutting Temperature compound (OCT).

Immunohistochemistry. Frozen sections of carotid arteries were incubated with rabbit anti-VEGF antibody (Abcam) and detected with Alexa-546 conjugated donkey anti-rabbit antibody. Normal rabbit lgG was used as antibody control. For quantification, five sections from each animal were chosen. Six different fields were then imaged from each section at $\times 400$. The relative fluorescence intensity from each image was measured using Image ( $\mathrm{NIH}$, Bethesda, MA, USA). The ratio of fluorescence intensity compared with AdGFP-treated uninjured control was calculated. All ratios were then averaged to generate the mean and S.D. for that animal. The means were then averaged and the S.E.M. was calculated for each group of animals.

TUNEL assay. Terminal deoxynucleotidyl transferase dUTP nick end labeling (TUNEL) assay was performed using an in situ cell death detection kit (Roche, Indianapolis, IN, USA). Frozen sections of carotid arteries were stained with the kit to assess DNA fragmentation as an indicator for cell apoptosis. For quantification, five sections from each animal were chosen. Six different fields were then imaged from each section at $\times 400$, and two independent investigators then manually counted the number of positive as well as the total number of cells. This was a binary decision. Cells were either positive or negative. All ratios were then averaged to generate the mean and S.D. for that animal. The means were then averaged and the S.E.M. was calculated for each group of animals.

Real-time PCR analysis. Total RNA was isolated from cultured cells using Trizol reagent (Invitrogen) according to the manufacturer's protocol. Stabilization of RNA harvested from arteries was performed directly using the RNAlater RNA Stabilization Reagent (Qiagen, Valencia, CA, USA) following the manufacturer's instructions. RNA was isolated using Rneasy Plus Mini Kit (Qiagen). Potential contaminating genomic DNA was removed by using gDNA Eliminator columns provided in the kit. RNA $(2 \mu \mathrm{g})$ was used for the first-strand CDNA synthesis (Applied Biosystems, Carlsbad, CA, USA). Quantitative RT-PCR was performed using the 7500 Fast Real-Time PCR System (Applied Biosystems). Each CDNA template was amplified in triplicate using SYBR Green PCR Master Mix (Applied Biosystems) with gene-specific primers.

Statistical analysis. Statistical analysis was conducted using a one-way analysis of variance (ANOVA) and values were presented as mean \pm S.E.M. derived from at least three independent experiments, unless otherwise stated. If significant, the ANOVA was followed by Tukey's multiple comparison test. A $P$-value of $<0.05$ is regarded as statistically significant.

\section{Conflict of Interest}

The authors declare no conflict of interest.

Acknowledgements. We thank Qiwei Wang, Stephanie Morgan, Shakti Goel, and Sarah R Franco for technical assistance and proofreading of the manuscript. This work was supported by a National Heart, Lung, Blood Institute R01 Grant (HL068673, to KCK) and a T32 training Grant (HL-110853 to KCK)

1. Suwanabol PA, Kent KC, Liu B. TGF-beta and restenosis revisited: a Smad link. J Surg Res 2011; 167: 287-297.

2. Tsai S, Hollenbeck ST, Ryer EJ, Edlin R, Yamanouchi D, Kundi R et al. TGF-beta through Smad3 signaling stimulates vascular smooth muscle cell proliferation and neointimal formation. Am J Physiol Heart Circ Physiol 2009; 297: H540-H549.

3. McCaffrey TA, Consigli S, Du B, Falcone DJ, Sanborn TA, Spokojny AM et al. Decreased type II/type I TGF-beta receptor ratio in cells derived from human atherosclerotic lesions. Conversion from an antiproliferative to profibrotic response to TGF-beta1. J Clin Invest 1995; 96: 2667-2675

4. Perlman H, Sata M, Krasinski K, Dorai T, Buttyan R, Walsh K. Adenovirus-encoded hammerhead ribozyme to Bcl-2 inhibits neointimal hyperplasia and induces vascular smooth muscle cell apoptosis. Cardiovasc Res 2000; 45: 570-578. 
5. Pollman MJ, Hall JL, Mann MJ, Zhang L, Gibbons GH. Inhibition of neointimal cell bcl-x expression induces apoptosis and regression of vascular disease. Nat Med 1998; 4: 222-227.

6. Si Y, Ren J, Wang P, Rateri DL, Daugherty A, Shi XD et al. Protein kinase C-delta mediates adventitial cell migration through regulation of monocyte chemoattractant protein-1 expression in a rat angioplasty model. Arterioscler Thromb Vasc Biol 2012; 32: 943-954.

7. Sata M, Perlman H, Muruve DA, Silver M, Ikebe M, Libermann TA et al. Fas ligand gene transfer to the vessel wall inhibits neointima formation and overrides the adenovirusmediated T cell response. Proc Natl Acad Sci USA 1998; 95: 1213-1217.

8. Han DK, Haudenschild CC, Hong MK, Tinkle BT, Leon MB, Liau G. Evidence for apoptosis in human atherogenesis and in a rat vascular injury model. Am J Pathol 1995; 147: 267-277.

9. Bochaton-Piallat ML, Gabbiani F, Redard M, Desmouliere A, Gabbiani G. Apoptosis participates in cellularity regulation during rat aortic intimal thickening. Am J Pathol 1995; 146: $1059-1064$

10. Hanke H, Strohschneider T, Oberhoff M, Betz E, Karsch KR. Time course of smooth muscle cell proliferation in the intima and media of arteries following experimental angioplasty. Circ Res 1990; 67: 651-659.

11. Kulms D, Schwarz T. Molecular mechanisms of UV-induced apoptosis. Photodermatol Photoimmunol Photomed 2000; 16: 195-201.

12. Shi $Y$, Massague J. Mechanisms of TGF-beta signaling from cell membrane to the nucleus. Cell 2003; 113: 685-700.

13. Hneino M, Bouazza L, Bricca G, Li JY, Langlois D. Density-dependent shift of transforming growth factor-beta-1 from inhibition to stimulation of vascular smooth muscle cell growth is based on unconventional regulation of proliferation, apoptosis and contact inhibition. $J$ Vasc Res 2009; 46: 85-97.

14. Orlandi A, Ropraz P, Gabbiani G. Proliferative activity and alpha-smooth muscle actin expression in cultured rat aortic smooth muscle cells are differently modulated by transforming growth factor-beta 1 and heparin. Exp Cell Res 1994; 214: 528-536.

15. Markowitz SD, Roberts AB. Tumor suppressor activity of the TGF-beta pathway in human cancers. Cytokine Growth Factor Rev 1996; 7: 93-102.

16. Bjorkerud $\mathrm{S}$. Effects of transforming growth factor-beta 1 on human arterial smooth muscle cells in vitro. Arterioscler Thromb 1991; 11: 892-902.

17. Christen $\mathrm{T}$, Bochaton-Piallat ML, Neuville $\mathrm{P}$, Rensen $\mathrm{S}$, Redard M, van Eys $\mathrm{G}$ et al. Cultured porcine coronary artery smooth muscle cells. A new model with advanced differentiation. Circ Res 1999; 85: 99-107.

18. Grainger DJ, Kirschenlohr HL, Metcalfe JC, Weissberg PL, Wade DP, Lawn RM. Proliferation of human smooth muscle cells promoted by lipoprotein(a). Science 1993; 260 : 1655-1658.

19. Majesky MW, Lindner V, Twardzik DR, Schwartz SM, Reidy MA. Production of transforming growth factor beta 1 during repair of arterial injury. J Clin Invest 1991; 88: 904-910.

20. Nabel EG, Shum L, Pompili VJ, Yang ZY, San H, Shu HB et al. Direct transfer of transforming growth factor beta 1 gene into arteries stimulates fibrocellular hyperplasia. Proc Natl Acad Sci USA 1993; 90: 10759-10763.

21. Suwanabol PA, Seedial SM, Shi X, Zhang F, Yamanouchi D, Roenneburg D et al. Transforming growth factor-beta increases vascular smooth muscle cell proliferation through the Smad3 and extracellular signal-regulated kinase mitogen-activated protein kinases pathways. J Vasc Surg 2012; 56: e441.

22. Roskoski Jr R. Vascular endothelial growth factor (VEGF) signaling in tumor progression. Crit Rev Oncol Hematol 2007; 62: 179-213.

23. Khurana R, Moons L, Shafi S, Luttun A, Collen D, Martin JF et al. Placental growth factor promotes atherosclerotic intimal thickening and macrophage accumulation. Circulation 2005; 111: 2828-2836.

24. Ferlosio A, Arcuri G, Doldo E, Scioli MG, De Falco S, Spagnoli LG et al. Age-related increase of stem marker expression influences vascular smooth muscle cell properties. Atherosclerosis 2012; 224: 51-57.

25. Orlandi A, Ferlosio A, Arcuri G, Scioli MG, De Falco S, Spagnoli LG. Flt-1 expression influences apoptotic susceptibility of vascular smooth muscle cells through the NF-kappaB/IAP-1 pathway. Cardiovasc Res 2010; 85: 214-223.

26. Edlin RS, Tsai S, Yamanouchi D, Wang C, Liu B, Kent KC. Characterization of primary and restenotic atherosclerotic plaque from the superficial femoral artery: potential role of Smad3 in regulation of SMC proliferation. J Vasc Surg 2009; 49: 1289-1295.

27. Jeon SH, Chae BC, Kim HA, Seo GY, Seo DW, Chun GT et al. Mechanisms underlying TGF-beta1-induced expression of VEGF and Flk-1 in mouse macrophages and their implications for angiogenesis. J Leukoc Biol 2007; 81: 557-566.

28. Hishikawa K, Oemar BS, Tanner FC, Nakaki T, Fujii T, Luscher TF. Overexpression of connective tissue growth factor gene induces apoptosis in human aortic smooth muscle cells. Circulation 1999; 100: 2108-2112.
29. McCaffrey TA, Du B, Fu C, Bray PJ, Sanborn TA, Deutsch E et al. The expression of TGF-beta receptors in human atherosclerosis: evidence for acquired resistance to apoptosis due to receptor imbalance. J Mol Cell Cardiol 1999; 31: 1627-1642.

30. Nataatmadja M, West J, West M. Overexpression of transforming growth factor-beta is associated with increased hyaluronan content and impairment of repair in Marfan syndrome aortic aneurysm. Circulation 2006; 114: I371-1377.

31. Ferns GA, Avades TY. The mechanisms of coronary restenosis: insights from experimental models. Int J Exp Pathol 2000; 81: 63-88.

32. Walsh K, Smith RC, Kim HS. Vascular cell apoptosis in remodeling, restenosis, and plaque rupture. Circ Res 2000; 87: 184-188.

33. Wolff RA, Ryomoto M, Stark VE, Malinowski R, Tomas JJ, Stinauer MA et al. Antisense to transforming growth factor-beta1 messenger RNA reduces vein graft intimal hyperplasia and monocyte chemotactic protein 1. J Vasc Surg 2005; 41: 498-508.

34. Lu P, Wang S, Cai W, Sheng J. TGF-beta $1 /$ Smad 3 expression and its effects on carotid intimal hyperplasia. Front Biosci (Elite Ed) 2012; 4: 2022-2028.

35. Kundi R, Hollenbeck ST, Yamanouchi D, Herman BC, Edlin R, Ryer EJ et al. Arterial gene transfer of the TGF-beta signalling protein Smad3 induces adaptive remodelling following angioplasty: a role for CTGF. Cardiovasc Res 2009; 84: 326-335.

36. Reis ED, Roque M, Cordon-Cardo C, Drobnjak M, Fuster V, Badimon JJ. Apoptosis, proliferation, and p27 expression during vessel wall healing: time course study in a mouse model of transluminal femoral artery injury. J Vasc Surg 2000; 32: 1022-1029.

37. Reddy MK, Vasir JK, Sahoo SK, Jain TK, Yallapu MM, Labhasetwar V. Inhibition of apoptosis through localized delivery of rapamycin-loaded nanoparticles prevented neointimal hyperplasia and reendothelialized injured artery. Circ Cardiovasc Interv 2008; 1: 209-216.

38. Asahara T, Chen D, Tsurumi $\mathrm{Y}$, Kearney M, Rossow S, Passeri J et al. Accelerated restitution of endothelial integrity and endothelium-dependent function after phVEGF165 gene transfer. Circulation 1996; 94: 3291-3302.

39. ardwaj S, Roy H, Heikura T, Yla-Herttuala S. VEGF-A, VEGF-D and VEGF$\mathrm{D}$ (DeltaNDeltaC) induced intimal hyperplasia in carotid arteries. Eur J Clin Invest 2005 35: 669-676.

40. Shiojima I, Walsh K. The role of vascular endothelial growth factor in restenosis: the controversy continues. Circulation 2004; 110: 2283-2286.

41. Ohtani K, Egashira K, Hiasa K, Zhao Q, Kitamoto S, Ishibashi M et al. Blockade of vascular endothelial growth factor suppresses experimental restenosis after intraluminal injury by inhibiting recruitment of monocyte lineage cells. Circulation 2004; 110: 2444-2452.

42. Koga J, Matoba T, Egashira K, Kubo M, Miyagawa M, Iwata E et al. Soluble Flt-1 gene transfer ameliorates neointima formation after wire injury in flt-1 tyrosine kinase-deficient mice. Arterioscler Thromb Vasc Biol 2009; 29: 458-464.

43. Hedman M, Hartikainen J, Syvanne M, Stjernvall J, Hedman A, Kivela A et al. Safety and feasibility of catheter-based local intracoronary vascular endothelial growth factor gene transfer in the prevention of postangioplasty and in-stent restenosis and in the treatment of chronic myocardial ischemia: phase II results of the Kuopio Angiogenesis Trial (KAT). Circulation 2003; 107: 2677-2683.

44. Ferrari G, Pintucci G, Seghezzi G, Hyman K, Galloway AC, Mignatti P. VEGF, a prosurvival factor, acts in concert with TGF-beta1 to induce endothelial cell apoptosis. Proc Natl Acad Sci USA 2006; 103: 17260-17265.

45. Sanchez-Elsner T, Botella LM, Velasco B, Corbi A, Attisano L, Bernabeu C. Synergistic cooperation between hypoxia and transforming growth factor-beta pathways on human vascular endothelial growth factor gene expression. J Biol Chem 2001; 276: 38527-38535.

46. Leitges M, Mayr M, Braun U, Mayr U, Li C, Pfister G et al. Exacerbated vein graft arteriosclerosis in protein kinase $C \delta-$ null mice. J Clin Invest 2001; 108: $1505-1512$.

(i) (2) Cell Death and Disease is an open-access journal published by Nature Publishing Group. This work is licensed under a Creative Commons Attribution-NonCommercialShareAlike 3.0 Unported License. The images or other third party material in this article are included in the article's Creative Commons license, unless indicated otherwise in the credit line; if the material is not included under the Creative Commons license, users will need to obtain permission from the license holder to reproduce the material. To view a copy of this license, visit http://creativecommons.org/ licenses/by-nc-sa/3.0/ 